\title{
The Interplay Between Autophagy and Senescence in Anthracycline Cardiotoxicity
}

\author{
Michele Russo $^{1} \cdot$ Enrico Bono $^{1} \cdot$ Alessandra Ghigo ${ }^{1}$ (i) \\ Accepted: 19 May 2021 / Published online: 3 June 2021 \\ (C) The Author(s) 2021
}

\begin{abstract}
Purpose of Review Doxorubicin (DOXO) is a highly effective chemotherapeutic drug employed for the treatment of a wide spectrum of cancers, spanning from solid tumours to haematopoietic malignancies. However, its clinical use is hampered by severe and dose-dependent cardiac side effects that ultimately lead to heart failure (HF).

Recent Findings Mitochondrial dysfunction and oxidative stress are well-established mechanisms of DOXO-induced cardiotoxicity, although recent evidence suggests that deregulation of other biological processes, like autophagy, could be involved. It is increasingly recognized that autophagy deregulation is intimately interconnected with the initiation of detrimental cellular responses, including autosis and senescence, raising the possibility of using autophagy modulators as well as senolytics and senomorphics for preventing DOXO cardiotoxicity.

Summary This review aims at providing an overview of the signalling pathways that are common to autophagy and senescence, with a special focus on how the relationship between these two processes is deregulated in response to cardiotoxic treatments. Finally, we will discuss the potential therapeutic utility of drugs modulating autophagy and/or senescence for counteracting DOXO cardiotoxicity.
\end{abstract}

Keywords Cardiotoxicity $\cdot$ Autophagy $\cdot$ Senescence $\cdot$ Doxorubicin $\cdot$ Cardio-Oncology

\section{Introduction}

Anthracyclines are a well-known class of antibiotics commonly used in the clinic as chemotherapy drugs because of their cytotoxic proprieties. Doxorubicin (DOXO) is the most potent member of the family that includes daunorubicin, epirubicin and idarubicin. Although several new-generation targeted therapies have been developed for the treatment of cancer, DOXO still remains the first-line treatment against a broad spectrum of solid tumours and haematopoietic malignancies. However, the clinical use of DOXO is often hampered by the onset of dose-dependent cardiovascular complications,

Michele Russo and Enrico Bono contributed equally to this work.

This article is part of the Topical Collection on Translational Research in Heart Failure

\section{Alessandra Ghigo}

Alessandra.ghigo@unito.it

1 Department of Molecular Biotechnology and Health Sciences, Molecular Biotechnology Center, University of Torino, Via Nizza 52, 10126 Torino, Italy usually occurring within 1 year from the completion of the treatment [1]. In the last decade, with the blooming of cardio-oncology, different strategies aimed at limiting or preventing the cardiotoxic effects of anthracyclines are being developed, including the use of antioxidant molecules designed to block DOXO-related oxidative stress [2•]. Unfortunately, although these compounds have proven successful in experimental animal models, they failed to show significant clinical benefits. The only drug approved by the FDA for the treatment of anthracycline cardiotoxicity is the anti-oxidant and iron chelator dexrazoxane, whose efficacy and safety have long been debated [3].

The failure of clinical trials with antioxidants has indicated that other molecular mechanisms besides oxidative stress likely account for the cardiac side effects of anthracyclines. Among the alternative mechanisms that have been extensively investigated in the last 5 years is autophagy, a cellular recycling process whose alteration has already been linked to a number of cardiovascular diseases (CVDs) [4]. Although the role of autophagy in DOXO cardiotoxicity has long been controversial, mainly as a consequence of the diversity of the experimental models used [5•], the prevailing 
view is that autophagy is impaired by DOXO and that means of restoring adequate levels of autophagy could be exploited to prevent or treat cardiotoxicity [6••]. Of note, drugs modulating autophagy have already been tested as potential treatments for other pathological conditions, including neurodegenerative disorders, metabolic diseases, tumorigenesis, as well as ageing-related CVDs [7, 8], and could be repurposed for mitigating DOXO-induced cardiotoxicity [9•].

Intriguingly, deregulation of autophagy, along with other hallmarks of anthracycline-mediated injury, like activation of the DNA damage response and epigenetic reprogramming, is one of the key features of senescence. This is increasingly recognized as a stress and damage response with a clear pathogenic role, also occurring in non-dividing and terminally differentiated cells, like cardiomyocytes [10••]. Accordingly, emerging evidence suggests that persistence of senescent cells could be a major cause of cardiotoxicity and that elimination of such cell subpopulations could help limit the cardiac side effects associated to the use of doxorubicin $[11 \bullet \bullet, 12]$.

Here, we will summarize how autophagy and senescence are interconnected and how their deregulation could contribute to anthracycline cardiotoxicity. Finally, we will speculate on how drugs targeting autophagy, senescence, or both could be exploited for preventing and treating cardiac complications of anthracycline-based anti-cancer regimens.

\section{Autophagy at the Crossroad of Cell Survival and Senescence in DOXO-Mediated Cardiotoxicity}

Autophagy is an essential process for the maintenance of cellular homeostasis. Under physiological conditions, autophagy is maintained at low levels, being increased in response to a wide spectrum of stress stimuli [13]. Autophagy is characterized by the formation of the autophagosome, a spherical structure with double-layered membranes that engulf dysfunctional cellular components, including organelles, allowing their elimination through the fusion with the lysosome. This structure is referred to as the autophagolysosome and represents the functional unit of the autophagy machinery. The entire process consists of five steps (initiation, nucleation, elongation, maturation and degradation) and requires the recruitment of autophagy-related genes (ATG) proteins [14]. The process is controlled by AMPK and mTOR that are the main upstream regulators which promote and inhibit ULK-1 activity, respectively (Fig. 1). ULK1, also known as ATG1, is the protein that triggers autophagy initiation by phosphorylating and positively regulating Beclin-1 [15]. On the other hand, Beclin1 activity is suppressed by $\mathrm{Bcl} 2$ after pro-survival stimuli, acting as an early check point of autophagy regulation [16]. These steps are crucial to the assembly of the ULK1/Beclin-1/Atg14L/ Vps34/Vps15 complex that is required to the autophagosome formation. The vacuolar protein sorting 34 (Vps34) triggers the production of phosphatidyl inositol 3-phosphate (PI3P) which, in turn, promotes the recruitment of further ATG proteins, such as ATG18, ATG20, ATG21 and ATG24, ultimately inducing phagosome elongation [17]. Autophagosome maturation is mediated by microtubule-associated protein 1 light chain 3 (LC3) that, in cells, is found in a cytosolic (LC3-I) and transmembrane (LC3-II) form. LC3-II is the result of ATG4mediated proteolytic cleavage at the C-terminus of LC3-I and subsequent conjugation of phosphatidylethanolamine (PE) [18]. These modifications generate an insoluble domain that enables the intercalation of LC3-II into the double membrane of the native phagosome, driving the recruitment in situ of proteins carrying an LC3-II-interacting domain (LIR) [19]. The most studied protein bearing a LIR domain is sequestosome-1, also referred to as p62, that is responsible of selecting ubiquitinated proteins that are destinated to degradation [20]. Other proteins carrying LIR domains, including NBR1, TRAF2 and SMURF1, can participate to the process [21]. This mechanism is highly conserved within eukaryotic cells, and despite the evolutionary divergencies described among species in autophagy-related genes [22], they show high similarity in mammals. For this reason, alterations of the autophagic flux have been found in many pathological conditions [23].

In the heart, the process of autophagy ensures a good plasticity of the tissue in response to a wide range of stressors. In fact, the replacement of damaged organelles, degradation of long-lived/misfolded proteins and mobilization of alternative energetic sources through autophagy are necessary for the homeostasis of terminally differentiated/post-mitotic cells, such as cardiomyocytes, where cellular replication is not an option [24]. On the other hand, chronic activation of autophagy is associated with maladaptive cardiac responses, such as ischemia/reperfusion (I/R) injury and haemodynamic stress [25-27].

The role of autophagy in DOXO-induced cardiomyopathy has been recently investigated and has led to conflicting results $[5,28]$. Lu et al. first described that DOXO injection in rats increases Beclin1 expression and autophagosome formation [29]. Additional studies confirmed this observation, showing an increased expression of autophagy-related markers, such as ATG proteins, LC3-II and p62 in DOXOtreated hearts [30-35]. In contrast, other studies support the view that DOXO treatment abolishes autophagy through the upstream inhibition of AMPK, the upregulation of mTOR and the diminished expression of autophagy-related genes [36-41]. These inconsistent conclusions are partly explained by technical variables, primarily the lack of accurate analysis of the autophagic flux in many studies that draw their conclusions simply on the basis of an analysis of the expression levels of proteins involved in autophagosome formation, such as LC3-II and p62. Moreover, the use of different protocols 


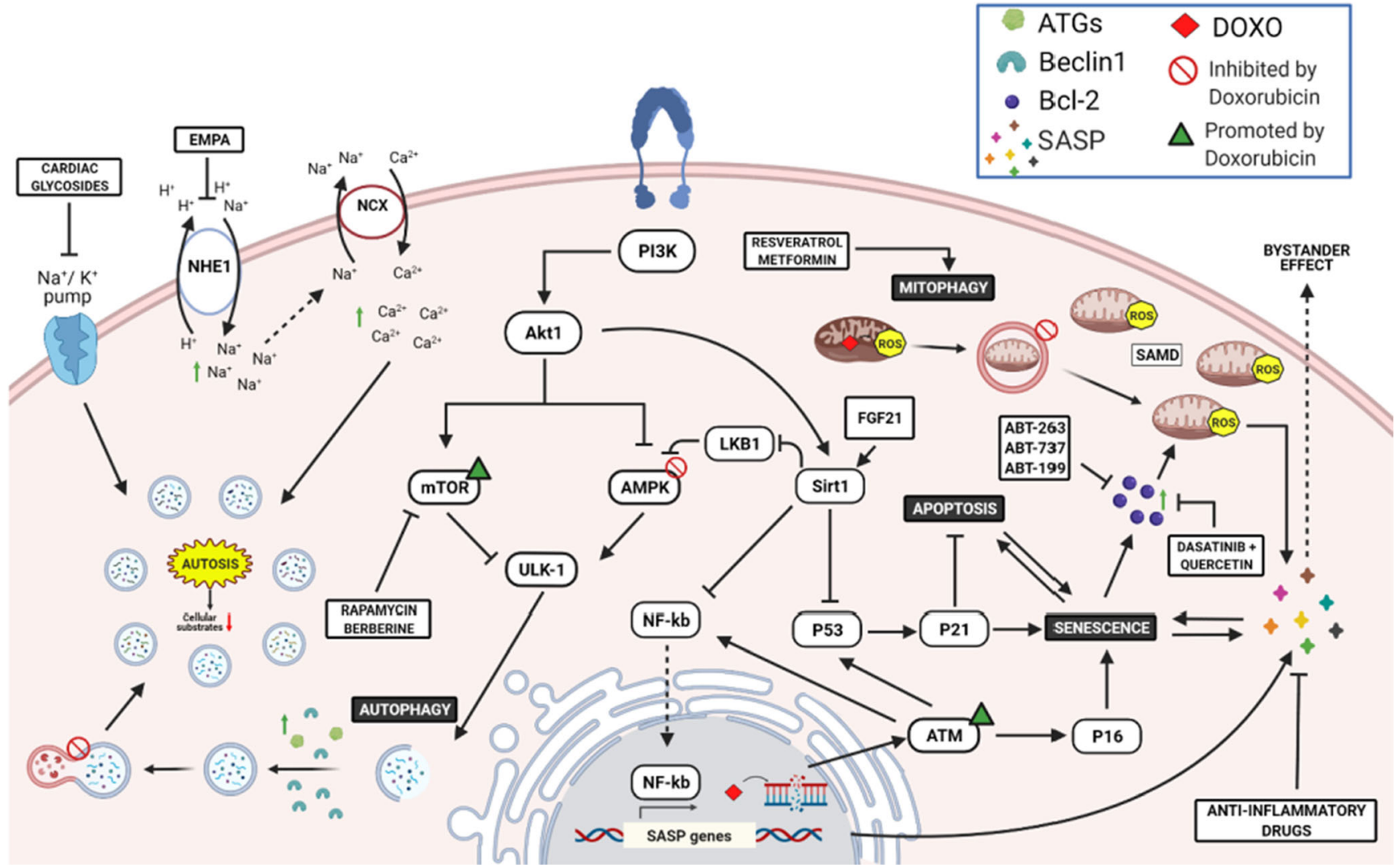

Fig. 1 Mechanisms of DOXO-induced senescence. DOXO-mediated DNA damage triggers activation of the p53/21 axis, promoting transition to senescence. Senescence is later endorsed by activation of $\mathrm{p} 16^{\mathrm{INK} 4 \mathrm{a}}$ pathways, favouring pro-inflammatory SAPS factors expression, which, in turn, are exaggerated by an accumulation of dysfunctional mitochondria and ROS production (SAMD). Thus, administration of senomorphics and senolytics provides beneficial effects, restoring mitophagy or specifically killing/depleting senescent cells, respectively. On the other hand, DOXO-mediated blockade of autophagosome-lysosome fusion leads to an aberrant accumulation of autophagosomes, triggering autosis. Finally, EMPA and cardiac glycosides ameliorate intracellular ion homeostasis, restoring autophagic flux. This figure was created with BioRender.com

et al. suggests that an additional mechanism behind the cardioprotection of p53 knock-out mice could be the preservation of mitochondrial autophagy since DOXO-mediated activation of p53 exaggerates ROS production and in turn impairs Parkin-mediated mitophagy. Of note, p53-deficient hearts are protected not only against DOXO-induced cardiotoxicity but from the functional cardiac decline observed with age, a process that is mechanistically linked to induction of senescence [47]. Therefore, p53-dependent disturbance of mitophagy and clearance of damaged mitochondria is a key process guiding the fate of cardiomyocytes towards survival, apoptosis or senescence $[6,45]$.

In further support of a functional connection between the processes of autophagy and senescence, it has been shown that autophagy critically controls the turnover and the cellular localization of stress-induced senescence marker proteins, such as p16 ${ }^{\mathrm{INK} 4 \mathrm{a}}$. Coryell et al. demonstrated that besides being regulated at transcriptional lev$\mathrm{el}, \mathrm{p} 16^{\mathrm{INK} 4 \mathrm{a}}$ activity is finely tuned by the autophagylysosome pathway. Activation of this mechanism blocks $\mathrm{p} 16^{\mathrm{INK} 4 \mathrm{a}}$ translocation from the cytoplasm to the nucleus 
and inhibits the transition to senescence. Of note, this mechanism is impaired in response to several stress stimuli, including cell starvation, oxidative stress as well as chemotherapy treatment, all inhibiting $\mathrm{p} 16^{\mathrm{INK} 4 \mathrm{a}}$ degradation and promoting senescence [48].

The above-mentioned mechanism may explain the accumulation of senescent cells observed in cancer patients undergoing radiotherapy/chemotherapy regimen and associated with high risk of premature age-related cardiovascular complications [49••]. Clinical studies reported that patients receiving chemotherapy treatment have accumulation of $\mathrm{p} 16^{\mathrm{INK} 4 \mathrm{a}}$-positive cells in different tissues, including the heart [50-53], which is detected within 1 year from treatment interruption [52-54].

In the following paragraph, we will describe the role of senescence in cardiac cells and how this process is interconnected with autophagy regulation.

\section{DOXO Induces Senescence Through Mitophagy Dysregulation and Increased Oxidative Stress}

Discovered in 1961, senescence was originally identified as an age-dependent mechanism associated with reduction of telomerase activity in replicant cells [55]. Senescent cells, which can be identified based on the increased expression of senescence-associated- $\beta$-galactosidase (SA- $\beta$-gal), are characterized by high resistance to apoptotic and growth stimuli, associated to high expression of the pro-survival protein Bcl-2 and of the cyclin-dependent inhibitor of the cell cycle $\mathrm{p} 16^{\mathrm{INK} 4 \mathrm{~A}}$, respectively $[56,57]$. Interestingly, activation of the p53/p21 axis is described as an early marker of senescent transition, while $\mathrm{p} 16^{\mathrm{INK} 4 \mathrm{~A}}$ is required later to maintain the senescent phenotype [58] and acts as a point of no return (Fig. 1) [59]. Beyond cell cycle arrest, other features of senescent cells include changes in the morphology of the main cellular compartments, increased mitochondria contents and metabolic rearrangements [60].

Interestingly, the definition of senescence has been recently reconsidered, leading to the emerging concept that senescence is a cellular stress response triggered by different stressors, spanning from DNA damage, mitochondrial dysfunction and oxidative stress, all key hallmarks of chemotherapy- and radiotherapy-mediated cell injury [10••, 61]. Therapy-induced senescence (TIS) indeed represents one of the mechanisms whereby anticancer agents like anthracyclines and ionizing radiation kill tumour cells [49••, 62, 63]. However, recent findings highlight that TIS may be detrimental, promoting aggressive tumour relapse and negatively affecting normal cells [11••]. In agreement with this notion, accumulation of senescent cells in the heart has been proposed as a major cause of the late-onset cardiovascular complications observed in patients undergoing radiotherapy and anthracycline chemotherapy [49••].
Although senescence was originally described as restricted to replicant cells, this cellular response has been observed also in post-mitotic cells, such as neurons and cardiomyocytes. The pathophysiological relevance of this postmitotic cell senescence (PoMiCS) is still incompletely understood. On the one hand, acute stress-induced premature senescence (SIPS) might be beneficial in tissue healing and repair [64, 65], particularly in organs with limited regenerative capacity, such as the brain and the heart $[10 \bullet, 61]$. On the contrary, senescent cells may have a pathogenic role that is linked to their ability to secrete a number of pro-inflammatory factors, including cytokines, chemokines, growth factors and metalloproteinases, overall referred to as senescence-associated secretory phenotype (SASP) [66]. On the one side, these secreted factors promote short-term tissue homeostasis and repair, while on the other side, they may cause maladaptive tissue remodelling and tumorigenesis due to tissue inflammation and immune cell suppression [67•]. Additionally, SASP factors exert a paracrine action, referred to as 'bystander effect', inducing senescence of neighbour cells both in vitro [68] and in vivo [69, 70•] (Fig. 1).

In DOXO cardiotoxicity, this secretory phenotype is likely activated by ROS generation that ensues from the abnormal accumulation of dysfunctional mitochondria after anthracyclines exposure (Fig. 1) [67•]. Consistently with this view, CorreiaMelo et al. demonstrated that mitophagy-dependent depletion of mitochondria in senescent cells has reduced production of SASP without affecting cell cycle machinery $[71,72]$. This supports the hypothesis that mitochondrial ROS are key modulators of SAMD phenotype, promoting NF-KB-dependent transcription of SASP factors (Fig. 1) [73].

In further support of the notion that autophagy inhibition is a trigger of senescence, autophagy re-activation, through either dietary restriction or small molecules, has been demonstrated to improve mitochondrial function [74], counteract the SAMD phenotype $[71,75]$ and deplete senescent cells in different tissues [76] (Table 1). On these grounds, one may speculate that autophagy activators could be exploited for preventing the induction of senescence in DOXO-treated hearts. In the following paragraph, we will discuss how drugs targeting the process of autophagy can indirectly contribute to block the process of senescence in response to DOXO.

\section{Senomorphic Effect of Autophagy-Inducing Molecules}

Senomorphics are a class of molecules that revert the morphology of senescent cells. These agents specifically target pathways required for the maintenance of the senescent state, without interfering with the cell-cycle machinery. Of note, the majority of these molecules are autophagy modulators and thus inhibit senescence indirectly through reactivation of 
Table 1 Proposed mechanisms of senotherapeutic molecules in DOXO-induced premature senescence

\begin{tabular}{|c|c|c|c|}
\hline Class of molecule & Type of treatment & Biological effects & References \\
\hline \multirow[t]{4}{*}{ Senomorphs } & Resveratrol & $\begin{array}{l}\text { Preserves mitochondrial activity and prevents cAMP degradation through } \\
\text { activation of SIRT1/PI3K/Akt axis. }\end{array}$ & {$[77]$} \\
\hline & Metformin & Promotes AMPK activation via phosphorylation of Ser633 and Ser1177. & {$[78]$} \\
\hline & Rapamycin & Positive autophagy modulation by mTOR inhibition and AMPK activation. & {$[9 \cdot]$} \\
\hline & Berberine & Inhibits mTOR signalling and increases DOXO detoxification. & [79] \\
\hline \multirow[t]{5}{*}{ Senolytics } & Quercetin & $\begin{array}{l}\text { Positive metabolic modulation, iron chelating activity, apoptosis inhibition, } \\
\text { prevention of tissue remodelling and reduction of oxidative stress and inflammation. } \\
\text { Increases cardioprotective effect of Losartan. } \\
\text { Inhibits Bcl-2 in tumour and senescent cells. }\end{array}$ & {$[49,80-83]$} \\
\hline & Dasatinib + Quercetin & Increased killing of $\mathrm{p} 16^{+}$and $\mathrm{p} 21^{+}$senescent cells. & {$[84]$} \\
\hline & АВT263, АВT737 & Eliminates $\mathrm{p} 16^{+}$positive cells, inhibiting the activity of Bcl-2 and Bcl-xL. & {$[11 \bullet \bullet]$} \\
\hline & ABT-199 & $\begin{array}{l}\text { Prevents ABT-263-mediated thrombocytopenia manifestation in patients } \\
\text { through specific inhibition of Bcl- } 2 \text {. }\end{array}$ & {$[85]$} \\
\hline & Cardiac glycosides & Disrupt intracellular concentrations of $\mathrm{Na}^{+}, \mathrm{K}^{+}$and $\mathrm{H}^{+}$in senescent cells. & [86] \\
\hline
\end{tabular}

autophagy. These include mTOR inhibitors and AMPK activators, the master regulators of autophagy. Consistently with this, cardiac inhibition of mTOR showed beneficial effect on SIPS, inducing parkin-mediated mitophagy and enhancing mitochondria turn-over [87•]. Moreover, mTOR inhibitors, such as Rapamycin and Berberine, positively modulate AMPK-induced autophagy (Fig. 1) [9•]. Particularly, experimental results in rodents showed that Berberine pre-treatment prevent DOXO-induced cardiac damage [79, 88, 89]. However, the beneficial effect of Berberine is due to inhibition of doxorubicin metabolism and reduced accumulation of its toxic metabolite doxorubicinol in the heart [79], rather than AMPK activation [89]. Of note, the effect of AMPK modulators, such as metformin, is reported as an attractive strategy to prevent the cardiometabolic impairments provoked by DOXO [90•]. Turdi and colleagues showed that low-dose Metformin exerts an AMPK-mediated beneficial effect on ageing hearts, improving mitochondrial function and diminishing ROS production (Fig. 1) [78]. Indeed, AMPK plays a key role in response to reduced ATP levels caused by dysfunctional mitochondria in senescent cells, suppressing the NF-KB-mediated SASP production and improving cell survival [91]. Similarly, experimental evidence showed the cardioprotective effects of Fibroblast growth factor 21 (FGF21) against DOXO-induced cardiomyopathy via activation of SIRT1/LKB1/AMPK axis. One mechanistic study revealed that FGF21 treatment enhances SIRT1-mediated inhibition of LKB1, an upstream negative modulator of AMPK, improving cardiac inflammation and mitochondrial respiration (Fig. 1) [92]. SIRT1 is a NAD ${ }^{+}$dependent histone deacetylase that regulates p53 activity and inhibits the transcriptional activity of NF-kB, whose function is compromised in cells with reduced $\mathrm{NAD}^{+} / \mathrm{NADH}$ ratio (Fig. 1) $[93,94]$. The reduction in $\mathrm{NAD}^{+}$metabolism represents an important feature of cells undergone SAMD and drives SASP release [95]. To this aim, $\mathrm{NAD}^{+}$supplementation and SIRT1 agonists were proposed as an optimal strategy in counteracting the pro-inflammatory senescence-associated secretome [95, 96]. Experimental evidence in vivo showed that resveratrol ameliorates cardiac function through activation of SIRT1/PI3K/Akt axis, preserving mitochondrial activity and preventing cAMP degradation [77]. Although the role of SIRT1 was not further investigated by Matsumura et al., this should delineate the beneficial effect of Resveratrol in response to the DOXO-mediated upregulation of p53 [97, 98]. Indeed, SIRT1 has been found to induce autophagy independently from the inhibitory effect of p53 and mTOR pathways [99, 100]. Furthermore, oral administration of the natural polyamine Spermidine exerts protective effects, ameliorating cardiac contraction, lowering cardiac hypertrophy and suppressing tissue inflammation. This cardioprotection is lost in mice where autophagy is pharmacologically or genetically abolished [101, 102]. Furthermore, genetic studies should clarify the additive epigenetic impact of Spermidine and Resveratrol, causing their inhibition of histone acetylases and activation of histone deacetylase respectively [101]. Our previous study showed that dietary supplementation of phenylalanine-butyramide, a potent histone deacetylase inhibitor, protects from DOXO-induced mitochondrial dysfunction and counteracts oxidative stress [103]. Overall, these findings suggest that improvement of the autophagic machinery can positively affects heart functions reverting the DOXO-associated SAMD phenotype.

\section{The New Frontier of Senolytics in DOXO Cardiotoxicity}

Senolytics are a new generation of compounds devised to specifically eliminate senescent cells, acting on pathways that protect senescent cells from apoptosis (Table 1). Compared to 
senomorphics, senolytics exert their pharmacological effect at lower concentrations, thus being well tolerated in animal models and holding great promise for clinical translation. Senolytic agents include natural compounds, such as quercentin, fisetin, piperlongumine, curcumin and cardiac glycosides as well as anticancer molecules, like dasatinib [104••]. Only three of them have so far been tested in preclinical models for their ability to deplete senescent cells in response to chemotherapy treatment and include dasatinib, quercetin and ABT263 (Navitoclax) [49••].

ABT263, along with A1331852 and A1155463, is an inhibitor of the anti-apoptotic proteins BCL-2 and BCL-xL. Demaria and co-workers demonstrated that ABT263 administration efficiently eliminates senescent cells after DOXO injection in transgenic p16-3MR tumour-bearing mice, in which p $16^{\mathrm{INK} 4}$ positive cells can be detected using live imaging techniques. ABT263-mediated depletion of senescent cells results in an improvement of the health status of animals undergoing chemotherapy regimen, associated with a reduction in SASPinduced systemic inflammation, diminished organ toxicity and preserved cardiac function [11••]. However, although ABT263 was designed to ameliorate the efficacy of the analogue molecule ABT-737, its inhibition of Bcl-xL causes thrombocytopenia. The Bcl-2 selective inhibitor ABT-199 (Venetoclax) has been developed to overcome this limitation, and results from phase I clinical trial showed encouraging results (Fig. 1) [85].

Another senolytic agent is quercetin, a plant-derived flavonoid that has been tested for its antineoplastic activity alone or in combination with DOXO. Preliminary experiments in vitro demonstrated that quercetin increases the antineoplastic activity of DOXO at low dose and protects non-tumoral cells [105, 106]. Several studies are ongoing to investigate the molecular mechanisms underlying the protective effects of quercetin against DOXO toxicity, which could include restoration of cellular metabolism, iron chelating activity, apoptosis inhibition, prevention of tissue remodelling and reduction of oxidative stress and inflammation [80, 81]. Additionally, quercetin administration augments the effect of cardioprotective molecules, such as losartan and resveratrol, in models of DOXOinduced cardiotoxicity $[82,83]$. Surprisingly, inhibition of the anti-apoptotic factor Bcl-2 is the main effect triggered by quercetin in cancer and senescent cells (Fig. 1) [49••]. Therefore, further studies are needed to elucidate the cell tropism of quercetin. Recently, a clinical trial showed that combined administration of quercetin and dasatinib reduces the number of senescent cells in patients with diabetic kidney disease [84]. Since the first article about senolytic agents was published in 2015 [107], this finding is the first evidence of their efficacy in humans and opens a new promising scenario on their introduction into clinical practice [108••].

Interestingly, cardiac glycosides, such as ouabain and digoxin, exert a potent senolytic activity by virtue of their ability to antagonize the $\mathrm{Na}^{+} / \mathrm{K}^{+}$-ATPase (Table 1) (Fig. 1). Indeed, senescent cells are more susceptible than normal cells to intracellular alterations of $\mathrm{Na}^{+}, \mathrm{K}^{+}$and $\mathrm{H}^{+}$concentrations [86]. Additionally, cardiac glycosides synergize with chemotherapy and increase the killing of tumoral senescent cells through the expression of the pro-apoptotic protein of the Bcl2-family, NOXA [109].

In addition to selective killing of senescent cells, ouabain also inhibits autosis, a recently described form of autophagyrelated cell death that is mediated by the $\mathrm{Na}^{+} / \mathrm{K}^{+}$-ATPase pump (Fig. 1) $[110,111]$. The role of autosis in the heart is still poorly characterized and limited to few indications coming from studies conducted in animal models of ischemia/ reperfusion (I/R) injury. Nah and colleagues showed that administration of ouabain protects from autosis-induced $\mathrm{I} / \mathrm{R}$ damage in humanized $\mathrm{Na}^{+} / \mathrm{K}^{+}$-ATPase-knock-in mice. However, although autosis-mediated cell death was initially associated to an increased autophagic flux, treatment with a selective autophagy inhibitor, bafilomycin A1, did not prevent the autotic process. This led to the hypothesis that cardiomyocytes that undergo autosis-dependent cell death may have their cellular functions compromised as a consequence of an excessive autophagosome formation (Fig.1). Indeed, the high amount of material required to assemble the double-membrane structure of autophagosomes may deprive cells of substrates necessary for building fundamental cellular organelles, such as mitochondria, endoplasmic reticulum, Golgi apparatus and plasma membrane [112]. Similarly, modulation of ion concentrations by empagliflozin, an inhibitor of the $\mathrm{Na}^{+} / \mathrm{H}^{+}$exchanger 1 (NHE1), prevents intracellular $\mathrm{Na}^{+}$ and $\mathrm{Ca}^{2+}$ overload and restores the autophagic flux, ultimately counteracting the deleterious activation of autosis in an animal model of I/R (Fig.1) [113]. Whether autosis is involved in chemotherapy-induced cardiotoxicity represents a new relevant field of investigation [114].

\section{Conclusion and Future Perspectives}

Overall, studies summarized herein demonstrate that autophagy deregulation represents a major mechanism underlying the cardiac adverse effects of chemotherapy, primarily anthracyclines. Intriguingly, recent findings have revealed how aberrant autophagy can trigger different maladaptive cellular responses, including senescence [115] and autosis [111]. On these bases, strategies aimed at restoring a physiological and balanced autophagic flux could indirectly act by preventing the initiation of those detrimental events and could be exploited for counteracting the cardiac side effects of anthracycline-based therapies. Furthermore, drugs directly favouring the elimination of senescent cells (senolytics) or reverting the senescent phenotype of cardiac cells (senomorphics) could be similarly exploited for the treatment 
of cardiotoxicity. Nevertheless, additional studies in preclinical models are required to conclusively demonstrate the feasibility of this latter approach.

Funding Open access funding provided by Università degli Studi di Torino within the CRUI-CARE Agreement.

\section{Declarations}

Conflict of Interest A.G. is co-founder and stakeholder of Kither Biotech, a pharmaceutical product company focused on respiratory medicine not in conflict with statements in this review. The other authors report no conflicts.

Human and Animal Rights and Informed Consent This article does not contain any studies with human or animal subjects performed by any of the authors.

Open Access This article is licensed under a Creative Commons Attribution 4.0 International License, which permits use, sharing, adaptation, distribution and reproduction in any medium or format, as long as you give appropriate credit to the original author(s) and the source, provide a link to the Creative Commons licence, and indicate if changes were made. The images or other third party material in this article are included in the article's Creative Commons licence, unless indicated otherwise in a credit line to the material. If material is not included in the article's Creative Commons licence and your intended use is not permitted by statutory regulation or exceeds the permitted use, you will need to obtain permission directly from the copyright holder. To view a copy of this licence, visit http://creativecommons.org/licenses/by/4.0/.

\section{References}

Papers of particular interest, published recently, have been highlighted as:

- Of importance

-• Of major importance

1. Cardinale D, Colombo A, Bacchiani G, Tedeschi I, Meroni CA, Veglia F, et al. Early detection of anthracycline cardiotoxicity and improvement with heart failure therapy. Circulation. 2015;131(22):1981-8. https://doi.org/10.1161/ CIRCULATIONAHA.114.013777.

2. Carrasco R, Castillo RL, Gormaz JG, Carrillo M, Thavendiranathan P. Role of oxidative stress in the mechanisms of anthracycline-induced cardiotoxicity: effects of preventive strategies. Oxidative medicine and cellular longevity. 2021;2021:8863789. https://doi.org/10.1155/2021/8863789. Collection of new therapeutic strategies aimed to prevent antracycline-induce redox unbalance.

3. Dewilde S, Carroll K, Nivelle E, Sawyer J. Evaluation of the costeffectiveness of dexrazoxane for the prevention of anthracyclinerelated cardiotoxicity in children with sarcoma and haematologic malignancies: a European perspective. Cost effectiveness and resource allocation : C/E. 2020;18:7. https://doi.org/10.1186/ s12962-020-0205-4.

4. Orogo AM, Gustafsson AB. Therapeutic targeting of autophagy: potential and concerns in treating cardiovascular disease.
Circulation research. 2015;116(3):489-503. https://doi.org/10. 1161/CIRCRESAHA.116.303791.

5. Li M, Russo M, Pirozzi F, Tocchetti CG, Ghigo A. Autophagy and cancer therapy cardiotoxicity: from molecular mechanisms to therapeutic opportunities. Biochimica et biophysica acta Molecular cell research. 2020;1867(3):118493. https://doi.org/ 10.1016/j.bbamcr.2019.06.007. Broad overview of the role of autophagy in the context of antracyclines-induced cardiotoxicity.

6.• Wallace KB, Sardao VA, Oliveira PJ. Mitochondrial determinants of doxorubicin-induced cardiomyopathy. Circulation research. 2020;126(7):926-41. https://doi.org/10.1161/CIRCRESAHA. 119.314681. A recent overview that extensively describes the impact of autophagy/mitophagy disturbance induced by DOXO.

7. Yang Y, Klionsky DJ. Autophagy and disease: unanswered questions. Cell death and differentiation. 2020;27(3):858-71. https:// doi.org/10.1038/s41418-019-0480-9.

8. Mercurio V, Cuomo A, Cadeddu Dessalvi C, Deidda M, Di Lisi $\mathrm{D}$, Novo G, et al. Redox imbalances in ageing and metabolic alterations: implications in cancer and cardiac diseases. An Overview from the Working Group of Cardiotoxicity and Cardioprotection of the Italian Society of Cardiology (SIC). Antioxidants. 2020;9(7). https://doi.org/10.3390/antiox9070641.

9. Ren J, Zhang Y. Targeting autophagy in aging and aging-related cardiovascular diseases. Trends in pharmacological sciences. 2018;39(12):1064-76. https://doi.org/10.1016/j.tips.2018.10. 005. Description of the mechanisms of autophagy-inducing molecules in prevention of senescence.

10.• von Zglinicki T, Wan T, Miwa S. Senescence in post-mitotic cells: a driver of aging? Antioxidants \& redox signaling. 2021;34(4): 308-23. https://doi.org/10.1089/ars.2020.8048. New emerging insights of senescent post-mitotic cells.

11.• Demaria M, O'Leary MN, Chang J, Shao L, Liu S, Alimirah F, et al. Cellular senescence promotes adverse effects of chemotherapy and cancer relapse. Cancer discovery. 2017;7(2):165-76. https://doi.org/10.1158/2159-8290.CD-16-0241. First experimental study showing the beneficial effect of senolytic agents against DOXO-induced cardiotoxicity.

12. Hernandez-Segura A, Nehme J, Demaria M. Hallmarks of cellular senescence. Trends in cell biology. 2018;28(6):436-53. https:// doi.org/10.1016/j.tcb.2018.02.001.

13. Chun Y, Kim J. Autophagy: an essential degradation program for cellular homeostasis and life. Cells. 2018;7(12). https://doi.org/10. 3390/cells7120278.

14. Eskelinen EL, Saftig P. Autophagy: a lysosomal degradation pathway with a central role in health and disease. Biochimica et biophysica acta. 2009;1793(4):664-73. https://doi.org/10.1016/j. bbamcr.2008.07.014.

15. Kim J, Kundu M, Viollet B, Guan KL. AMPK and mTOR regulate autophagy through direct phosphorylation of Ulk1. Nature cell biology. 2011;13(2):132-41. https://doi.org/10.1038/ ncb2152.

16. Pattingre S, Tassa A, Qu X, Garuti R, Liang XH, Mizushima N, et al. Bcl-2 antiapoptotic proteins inhibit Beclin 1-dependent autophagy. Cell. 2005;122(6):927-39. https://doi.org/10.1016/j.cell. 2005.07.002.

17. Ravikumar B, Sarkar S, Davies JE, Futter M, Garcia-Arencibia M, Green-Thompson ZW, et al. Regulation of mammalian autophagy in physiology and pathophysiology. Physiological reviews. 2010;90(4):1383-435. https://doi.org/10.1152/physrev.00030. 2009.

18. Runwal G, Stamatakou E, Siddiqi FH, Puri C, Zhu Y, Rubinsztein DC. LC3-positive structures are prominent in autophagy-deficient cells. Scientific reports. 2019;9(1):10147. https://doi.org/10.1038/ s41598-019-46657-z. 
19. Kabeya Y, Mizushima N, Ueno T, Yamamoto A, Kirisako T, Noda T, et al. LC3, a mammalian homologue of yeast Apg8p, is localized in autophagosome membranes after processing. The EMBO journal. 2000;19(21):5720-8. https://doi.org/10.1093/ emboj/19.21.5720.

20. He C, Klionsky DJ. Regulation mechanisms and signaling pathways of autophagy. Annual review of genetics. 2009;43:67-93. https://doi.org/10.1146/annurev-genet-102808-114910.

21. Koleini N, Kardami E. Autophagy and mitophagy in the context of doxorubicin-induced cardiotoxicity. Oncotarget. 2017;8(28): 46663-80. https://doi.org/10.18632/oncotarget.16944.

22. King JS. Autophagy across the eukaryotes: is S. cerevisiae the odd one out? Autophagy. 2012;8(7):1159-62. https://doi.org/10.4161/ auto. 20527

23. Levine B, Kroemer G. Autophagy in the pathogenesis of disease. Cell. 2008;132(1):27-42. https://doi.org/10.1016/j.cell.2007.12. 018 .

24. Schiattarella GG, Hill JA. Therapeutic targeting of autophagy in cardiovascular disease. Journal of molecular and cellular cardiology. 2016;95:86-93. https://doi.org/10.1016/j.yjmcc.2015.11. 019 .

25. Matsui Y, Takagi H, Qu X, Abdellatif M, Sakoda H, Asano T, et al. Distinct roles of autophagy in the heart during ischemia and reperfusion: roles of AMP-activated protein kinase and Beclin 1 in mediating autophagy. Circulation research. 2007;100(6):914-22. https://doi.org/10.1161/01.RES.0000261924.76669.36.

26. Berthiaume JM, Wallace KB. Adriamycin-induced oxidative mitochondrial cardiotoxicity. Cell biology and toxicology. 2007;23(1):15-25. https://doi.org/10.1007/s10565-006-0140-y.

27. Nakai A, Yamaguchi O, Takeda T, Higuchi Y, Hikoso S, Taniike $\mathrm{M}$, et al. The role of autophagy in cardiomyocytes in the basal state and in response to hemodynamic stress. Nature medicine. 2007;13(5):619-24. https://doi.org/10.1038/nm1574.

28. Dirks-Naylor AJ. The role of autophagy in doxorubicin-induced cardiotoxicity. Life sciences. 2013;93(24):913-6.

29. Lu L, Wu W, Yan J, Li X, Yu H, Yu X. Adriamycin-induced autophagic cardiomyocyte death plays a pathogenic role in a rat model of heart failure. International journal of cardiology. 2009;134(1):82-90. https://doi.org/10.1016/j.ijcard.2008.01.043.

30. Kobayashi S, Volden P, Timm D, Mao K, Xu X, Liang Q. Transcription factor GATA4 inhibits doxorubicin-induced autophagy and cardiomyocyte death. The Journal of biological chemistry. 2010;285(1):793-804. https://doi.org/10.1074/jbc. M109.070037.

31. Zhang Y, Kang YM, Tian C, Zeng Y, Jia LX, Ma X, et al. Overexpression of Nrdp1 in the heart exacerbates doxorubicininduced cardiac dysfunction in mice. PloS one. 2011;6(6): e21104. https://doi.org/10.1371/journal.pone.0021104.

32. Luo P, Zhu Y, Chen M, Yan H, Yang B, Yang X, et al. HMGB1 contributes to adriamycin-induced cardiotoxicity via upregulating autophagy. Toxicology letters. 2018;292:115-22. https://doi.org/10.1016/j.toxlet.2018.04.034.

33. Xu ZM, Li CB, Liu QL, Li P, Yang H. Ginsenoside Rg1 prevents doxorubicin-induced cardiotoxicity through the inhibition of autophagy and endoplasmic reticulum stress in mice. International journal of molecular sciences. 2018;19(11). https://doi.org/10. 3390/ijms19113658.

34. Zhang QL, Yang JJ, Zhang HS. Carvedilol (CAR) combined with carnosic acid (CAA) attenuates doxorubicin-induced cardiotoxicity by suppressing excessive oxidative stress, inflammation, apoptosis and autophagy. Biomedicine $\&$ pharmacotherapy $=$ Biomedecine $\&$ pharmacotherapie. 2019;109:71-83. https://doi.org/10.1016/j.biopha.2018.07.037.

35. Wang X, Wang XL, Chen HL, Wu D, Chen JX, Wang XX, et al. Ghrelin inhibits doxorubicin cardiotoxicity by inhibiting excessive autophagy through AMPK and p38-MAPK. Biochemical pharmacology. 2014;88(3):334-50. https://doi.org/10.1016/j.bcp. 2014.01.040.

36. Sishi BJ, Loos B, van Rooyen J, Engelbrecht AM. Autophagy upregulation promotes survival and attenuates doxorubicininduced cardiotoxicity. Biochemical pharmacology. 2013;85(1): 124-34. https://doi.org/10.1016/j.bcp.2012.10.005.

37. Kawaguchi T, Takemura G, Kanamori H, Takeyama T, Watanabe $\mathrm{T}$, Morishita K, et al. Prior starvation mitigates acute doxorubicin cardiotoxicity through restoration of autophagy in affected cardiomyocytes. Cardiovascular research. 2012;96(3):456-65. https://doi.org/10.1093/cvr/cvs282.

38. Xu X, Bucala R, Ren J. Macrophage migration inhibitory factor deficiency augments doxorubicin-induced cardiomyopathy. Journal of the American Heart Association. 2013;2(6):e000439. https://doi.org/10.1161/JAHA.113.000439.

39. Dutta D, Xu J, Dirain ML, Leeuwenburgh C. Calorie restriction combined with resveratrol induces autophagy and protects 26month-old rat hearts from doxorubicin-induced toxicity. Free radical biology \& medicine. 2014;74:252-62. https://doi.org/10. 1016/j.freeradbiomed.2014.06.011.

40. Song R, Yang Y, Lei H, Wang G, Huang Y, Xue W, et al. HDAC6 inhibition protects cardiomyocytes against doxorubicin-induced acute damage by improving alpha-tubulin acetylation. Journal of molecular and cellular cardiology. 2018;124:58-69. https://doi. org/10.1016/j.yjmcc.2018.10.007.

41. Li M, Sala V, De Santis MC, Cimino J, Cappello P, Pianca N, et al. Phosphoinositide 3-kinase gamma inhibition protects from anthracycline cardiotoxicity and reduces tumor growth. Circulation. 2018;138(7):696-711. https://doi.org/10.1161/ CIRCULATIONAHA.117.030352.

42.• Sawicki KT, Sala V, Prever L, Hirsch E, Ardehali H, Ghigo A. Preventing and treating anthracycline cardiotoxicity: new insights. Annual review of pharmacology and toxicology. 2021;61:30932. https://doi.org/10.1146/annurev-pharmtox-030620-104842. Up-to-date summary of mechanisms involved in DOXOinduced cardiotoxicity.

43. Zhu W, Zhang W, Shou W, Field LJ. P53 inhibition exacerbates late-stage anthracycline cardiotoxicity. Cardiovascular research. 2014;103(1):81-9. https://doi.org/10.1093/cvr/cvu118.

44. Nithipongvanitch R, Ittarat W, Velez JM, Zhao R, St Clair DK, Oberley TD. Evidence for p53 as guardian of the cardiomyocyte mitochondrial genome following acute adriamycin treatment. The journal of histochemistry and cytochemistry: official journal of the Histochemistry Society. 2007;55(6):629-639. doi:https://doi.org/ 10.1369/jhc.6A7146.2007.

45. Sahin E, Colla S, Liesa M, Moslehi J, Muller FL, Guo M, et al. Telomere dysfunction induces metabolic and mitochondrial compromise. Nature. 2011;470(7334):359-65. https://doi.org/10. 1038/nature09787.

46. Shizukuda Y, Matoba S, Mian OY, Nguyen T, Hwang PM. Targeted disruption of p53 attenuates doxorubicin-induced cardiac toxicity in mice. Molecular and cellular biochemistry. 2005;273(1-2):25-32. https://doi.org/10.1007/s11010-005-59058.

47. Hoshino A, Mita Y, Okawa Y, Ariyoshi M, Iwai-Kanai E, Ueyama T, et al. Cytosolic p53 inhibits Parkin-mediated mitophagy and promotes mitochondrial dysfunction in the mouse heart. Nature communications. 2013;4:2308. https://doi.org/10. 1038/ncomms 3308 .

48. Coryell PR, Goraya SK, Griffin KA, Redick MA, Sisk SR, Purvis JE. Autophagy regulates the localization and degradation of p16(INK4a). Aging cell. 2020;19(7):e13171. https://doi.org/10. 1111/acel.13171.

49.• Abdelgawad IY, Sadak KT, Lone DW, Dabour MS, Niedernhofer LJ, Zordoky BN. Molecular mechanisms and cardiovascular implications of cancer therapy-induced senescence. Pharmacology \& 
therapeutics. 2020;221:107751. https://doi.org/10.1016/j. pharmthera.2020.107751. Exhaustive report about the experimental models used to study the implications of senescent cells in chemotherapy-induced cardiotoxicity and the most relevant therapeutic approach.

50. Shachar SS, Deal AM, Reeder-Hayes KE, Nyrop KA, Mitin N, Anders CK, et al. Effects of breast cancer adjuvant chemotherapy regimens on expression of the aging biomarker, p16(INK4a). JNCI cancer spectrum. 2020;4(6):pkaa082. https://doi.org/10. 1093/jncics/pkaa082.

51. Piegari E, De Angelis A, Cappetta D, Russo R, Esposito G, Costantino S, et al. Doxorubicin induces senescence and impairs function of human cardiac progenitor cells. Basic research in cardiology. 2013;108(2):334. https://doi.org/10.1007/s00395-0130334-4.

52. Marcoux S, Le ON, Langlois-Pelletier C, Laverdiere C, Hatami A, Robaey P, et al. Expression of the senescence marker p16INK4a in skin biopsies of acute lymphoblastic leukemia survivors: a pilot study. Radiation oncology. 2013;8:252. https://doi.org/10.1186/ 1748-717X-8-252.

53. Sanoff HK, Deal AM, Krishnamurthy J, Torrice C, Dillon P, Sorrentino J, et al. Effect of cytotoxic chemotherapy on markers of molecular age in patients with breast cancer. Journal of the National Cancer Institute. 2014;106(4):dju057. https://doi.org/ 10.1093/jnci/dju057.

54. Rufini A, Tucci P, Celardo I, Melino G. Senescence and aging: the critical roles of p53. Oncogene. 2013;32(43):5129-43. https://doi. org/10.1038/onc.2012.640.

55. Hayflick L, Moorhead PS. The serial cultivation of human diploid cell strains. Experimental cell research. 1961;25:585-621. https:// doi.org/10.1016/0014-4827(61)90192-6.

56. Yosef R, Pilpel N, Tokarsky-Amiel R, Biran A, Ovadya Y, Cohen $\mathrm{S}$, et al. Directed elimination of senescent cells by inhibition of BCL-W and BCL-XL. Nature communications. 2016;7:11190. https://doi.org/10.1038/ncomms11190.

57. Chang J, Wang Y, Shao L, Laberge RM, Demaria M, Campisi J, et al. Clearance of senescent cells by ABT263 rejuvenates aged hematopoietic stem cells in mice. Nature medicine. 2016;22(1): 78-83. https://doi.org/10.1038/nm.4010.

58. Dulic V, Beney GE, Frebourg G, Drullinger LF, Stein GH. Uncoupling between phenotypic senescence and cell cycle arrest in aging p21-deficient fibroblasts. Molecular and cellular biology. 2000;20(18):6741-54. https://doi.org/10.1128/mcb.20.18.67416754.2000 .

59. Beausejour CM, Krtolica A, Galimi F, Narita M, Lowe SW, Yaswen P, et al. Reversal of human cellular senescence: roles of the p53 and p16 pathways. The EMBO journal. 2003;22(16): 4212-22. https://doi.org/10.1093/emboj/cdg417.

60. Cristofalo VJ, Pignolo RJ. Replicative senescence of human fibroblast-like cells in culture. Physiological reviews. 1993;73(3):617-38. https://doi.org/10.1152/physrev.1993.73.3. 617.

61.• Sapieha P, Mallette FA. Cellular senescence in postmitotic cells: beyond growth arrest, 2018. Trends in cell biology. 28(8):595607. https://doi.org/10.1016/j.tcb.2018.03.003. Examines the putative pathophysiological role of post-mitotic cellular senescence.

62. Ewald JA, Desotelle JA, Wilding G, Jarrard DF. Therapy-induced senescence in cancer. Journal of the National Cancer Institute. 2010;102(20):1536-46. https://doi.org/10.1093/jnci/djq364.

63. Roninson IB. Tumor cell senescence in cancer treatment. Cancer research. 2003;63(11):2705-15.

64. Li F, Huang Q, Chen J, Peng Y, Roop DR, Bedford JS, et al. Apoptotic cells activate the "phoenix rising" pathway to promote wound healing and tissue regeneration. Science signaling. 2010;3(110):ra13. https://doi.org/10.1126/scisignal.2000634.
65. Demaria M, Ohtani N, Youssef SA, Rodier F, Toussaint W, Mitchell JR, et al. An essential role for senescent cells in optimal wound healing through secretion of PDGF-AA. Developmental cell. 2014;31(6):722-33. https://doi.org/10.1016/j.devcel.2014. 11.012 .

66. Lujambio A. To clear, or not to clear (senescent cells)? That is the question. BioEssays: news and reviews in molecular, cellular and developmental biology. 2016;38(Suppl 1):S56-64. https://doi. org/10.1002/bies.201670910.

67. Korolchuk VI, Miwa S, Carroll B, von Zglinicki T. Mitochondria in cell senescence: is mitophagy the weakest link? EBioMedicine. 2017;21:7-13. https://doi.org/10.1016/j.ebiom.2017.03.020. Highlights mechanisms leading to mitophagy disturbance in cellular senescent transition.

68. Nelson G, Wordsworth J, Wang C, Jurk D, Lawless C, MartinRuiz C, et al. A senescent cell bystander effect: senescenceinduced senescence. Aging cell. 2012;11(2):345-9. https://doi. org/10.1111/j.1474-9726.2012.00795.x.

69. Acosta JC, Banito A, Wuestefeld T, Georgilis A, Janich P, Morton $\mathrm{JP}$, et al. A complex secretory program orchestrated by the inflammasome controls paracrine senescence. Nature cell biology. 2013;15(8):978-90. https://doi.org/10.1038/ncb2784.

70.• da Silva PFL, Ogrodnik M, Kucheryavenko O, Glibert J, Miwa S, Cameron K, et al. The bystander effect contributes to the accumulation of senescent cells in vivo. Aging cell. 2019;18(1):e12848. https://doi.org/10.1111/acel.12848. First in vivo evidence showing that senescent cells induce senescence in neighboring cells through the release of SASP factors.

71. Correia-Melo C, Marques FD, Anderson R, Hewitt G, Hewitt R, Cole J, et al. Mitochondria are required for pro-ageing features of the senescent phenotype. The EMBO journal. 2016;35(7):724-42. https://doi.org/10.15252/embj.201592862.

72. Kolesnik FA, Nikolaeva NV, Vinogradova TA, Riabokon AG. The work capacity of patients with chronic nonspecific lung diseases combined with ischemic heart disease. Vrachebnoe delo. 1989;(7):65-6.

73. Morgan MJ, Liu ZG. Crosstalk of reactive oxygen species and NF-kappaB signaling. Cell research. 2011;21(1):103-15. https:// doi.org/10.1038/cr.2010.178.

74. Miwa S, Jow H, Baty K, Johnson A, Czapiewski R, Saretzki G, et al. Low abundance of the matrix arm of complex I in mitochondria predicts longevity in mice. Nature communications. 2014;5: 3837. https://doi.org/10.1038/ncomms4837.

75. Demidenko ZN, Blagosklonny MV. Growth stimulation leads to cellular senescence when the cell cycle is blocked. Cell cycle. 2008;7(21):3355-61. https://doi.org/10.4161/cc.7.21.6919.

76. Wang C, Maddick M, Miwa S, Jurk D, Czapiewski R, Saretzki G, et al. Adult-onset, short-term dietary restriction reduces cell senescence in mice. Aging. 2010;2(9):555-66. https://doi.org/10. 18632/aging.100196.

77. Zhang Y, Mi SL, Hu N, Doser TA, Sun A, Ge J, et al. Mitochondrial aldehyde dehydrogenase 2 accentuates aginginduced cardiac remodeling and contractile dysfunction: role of AMPK, Sirt1, and mitochondrial function. Free radical biology \& medicine. 2014;71:208-20. https://doi.org/10.1016/j. freeradbiomed.2014.03.018.

78. Turdi S, Fan X, Li J, Zhao J, Huff AF, Du M, et al. AMP-activated protein kinase deficiency exacerbates aging-induced myocardial contractile dysfunction. Aging cell. 2010;9(4):592-606. https:// doi.org/10.1111/j.1474-9726.2010.00586.x.

79. Hao G, Yu Y, Gu B, Xing Y, Xue M. Protective effects of berberine against doxorubicin-induced cardiotoxicity in rats by inhibiting metabolism of doxorubicin. Xenobiotica; the fate of foreign compounds in biological systems. 2015;45(11):1024-9. https://doi.org/10.3109/00498254.2015.1034223. 
80. Zakaria N, Khalil SR, Awad A, Khairy GM. Quercetin reverses altered energy metabolism in the heart of rats receiving adriamycin chemotherapy. Cardiovascular toxicology. 2018;18(2):109-19. https://doi.org/10.1007/s12012-017-9420-4.

81. Kaiserova H, Simunek T, van der Vijgh WJ, Bast A, Kvasnickova E. Flavonoids as protectors against doxorubicin cardiotoxicity: role of iron chelation, antioxidant activity and inhibition of carbonyl reductase. Biochimica et biophysica acta. 2007;1772(9): 1065-74. https://doi.org/10.1016/j.bbadis.2007.05.002.

82. Matouk AI, Taye A, Heeba GH, El-Moselhy MA. Quercetin augments the protective effect of losartan against chronic doxorubicin cardiotoxicity in rats. Environmental toxicology and pharmacology. 2013;36(2):443-50. https://doi.org/10.1016/j.etap.2013.05. 006

83. Cote B, Carlson LJ, Rao DA, Alani AWG. Combinatorial resveratrol and quercetin polymeric micelles mitigate doxorubicin induced cardiotoxicity in vitro and in vivo. Journal of controlled release: official journal of the Controlled Release Society. 2015;213:128-33. https://doi.org/10.1016/j.jconrel.2015.06.040.

84. Hickson LJ, Langhi Prata LGP, Bobart SA, Evans TK, Giorgadze N, Hashmi SK, et al. Senolytics decrease senescent cells in humans: preliminary report from a clinical trial of Dasatinib plus Quercetin in individuals with diabetic kidney disease. EBioMedicine. 2019;47:446-56. https://doi.org/10.1016/j.ebiom. 2019.08.069.

85. Tanos R, Karmali D, Nalluri S, Goldsmith KC. Select Bcl-2 antagonism restores chemotherapy sensitivity in high-risk neuroblastoma. BMC cancer. 2016;16:97. https://doi.org/10.1186/s12885016-2129-0.

86. Triana-Martinez F, Picallos-Rabina P, Da Silva-Alvarez S, Pietrocola F, Llanos S, Rodilla V, et al. Identification and characterization of Cardiac Glycosides as senolytic compounds. Nature communications. 2019;10(1):4731. https://doi.org/10.1038/ s41467-019-12888-X.

87. Manzella N, Santin Y, Maggiorani D, Martini H, Douin-Echinard $\mathrm{V}$, Passos JF, et al. Monoamine oxidase-A is a novel driver of stress-induced premature senescence through inhibition of parkin-mediated mitophagy. Aging cell. 2018;17(5):e12811. https://doi.org/10.1111/acel.12811. Authors elucidate a new molecular mechanism that endorses mitochondria-derived ROS during premature senescence initiation.

88. Zhao X, Zhang J, Tong N, Liao X, Wang E, Li Z, et al. Berberine attenuates doxorubicin-induced cardiotoxicity in mice. The Journal of international medical research. 2011;39(5):1720-7. https://doi.org/10.1177/147323001103900514.

89. Lv X, Yu X, Wang Y, Wang F, Li H, Wang Y, et al. Berberine inhibits doxorubicin-triggered cardiomyocyte apoptosis via attenuating mitochondrial dysfunction and increasing Bcl-2 expression. PloS one. 2012;7(10):e47351. https://doi.org/10.1371/journal. pone.0047351.

90. Russo M, Della Sala A, Tocchetti CG, Porporato PE, Ghigo A. Metabolic aspects of anthracycline cardiotoxicity. Current treatment options in oncology. 2021;22(2):18. https://doi.org/10.1007/ s11864-020-00812-1. Recent overview of the detrimental impact of anthracycline treatment on cardiac metabolism.

91. Salminen A, Kaarniranta K. AMP-activated protein kinase (AMPK) controls the aging process via an integrated signaling network. Ageing research reviews. 2012;11(2):230-41. https:// doi.org/10.1016/j.arr.2011.12.005.

92. Wang S, Wang Y, Zhang Z, Liu Q, Gu J. Cardioprotective effects of fibroblast growth factor 21 against doxorubicin-induced toxicity via the SIRT1/LKB1/AMPK pathway. Cell death \& disease. 2017;8(8):e3018. https://doi.org/10.1038/cddis.2017.410.

93. Sasaki T, Maier B, Bartke A, Scrable H. Progressive loss of SIRT1 with cell cycle withdrawal. Aging cell. 2006;5(5):413-22. https:// doi.org/10.1111/j.1474-9726.2006.00235.x.
94. Imai S, Guarente L. NAD+ and sirtuins in aging and disease. Trends in cell biology. 2014;24(8):464-71. https://doi.org/10. 1016/j.tcb.2014.04.002.

95. Nacarelli T, Lau L, Fukumoto T, Zundell J, Fatkhutdinov N, Wu $\mathrm{S}$, et al. $\mathrm{NAD}(+)$ metabolism governs the proinflammatory senescence-associated secretome. Nature cell biology. 2019;21(3):397-407. https://doi.org/10.1038/s41556-019-02874.

96. Wiley CD. Bubble Bubble, Senescent cells are a cauldron of tumor trouble. Cancer research. 2020;80(16):3193-4. https://doi. org/10.1158/0008-5472.CAN-20-1811.

97. Matsumura N, Zordoky BN, Robertson IM, Hamza SM, Parajuli $\mathrm{N}$, Soltys CM, et al. Co-administration of resveratrol with doxorubicin in young mice attenuates detrimental late-occurring cardiovascular changes. Cardiovascular research. 2018;114(10): 1350-9. https://doi.org/10.1093/cvr/cvy064.

98. Abid S, Lipskaia L, Adnot S. Anthracycline cardiotoxicity: looking for new therapeutic approaches targeting cell senescence? Cardiovascular research. 2018;114(10):1304-5. https://doi.org/ $10.1093 / \mathrm{cvr} / \mathrm{cvy} 108$. This work highlights the need to target anthracycline-induced senescent cells.

99. Wu WY, Cui YK, Hong YX, Li YD, Wu Y, Li G, et al. Doxorubicin cardiomyopathy is ameliorated by acacetin via Sirt1-mediated activation of AMPK/Nrf2 signal molecules. Journal of cellular and molecular medicine. 2020;24(20):1214153. https://doi.org/10.1111/jcmm.15859.

100. Morselli E, Maiuri MC, Markaki M, Megalou E, Pasparaki A, Palikaras K, et al. Caloric restriction and resveratrol promote longevity through the Sirtuin-1-dependent induction of autophagy. Cell death \& disease. 2010;1:e10. https://doi.org/10.1038/cddis. 2009.8 .

101. Morselli E, Galluzzi L, Kepp O, Criollo A, Maiuri MC, Tavernarakis N, et al. Autophagy mediates pharmacological lifespan extension by spermidine and resveratrol. Aging. 2009;1(12):961-70. https://doi.org/10.18632/aging.100110.

102. Eisenberg T, Abdellatif M, Schroeder S, Primessnig U, Stekovic $\mathrm{S}$, Pendl T, et al. Cardioprotection and lifespan extension by the natural polyamine spermidine. Nature medicine. 2016;22(12): 1428-38. https://doi.org/10.1038/nm.4222.

103. Russo M, Guida F, Paparo L, Trinchese G, Aitoro R, Avagliano C, et al. The novel butyrate derivative phenylalanine-butyramide protects from doxorubicin-induced cardiotoxicity. European journal of heart failure. 2019;21(4):519-28. https://doi.org/10.1002/ejhf. 1439.

104.• Muñoz-Espin R. D., Demaria M, editors. Senolytics in disease, ageing and longevity, healthy ageing and longevity book series (HAL, volume 11), Springer Nature 2020. A complete overview of the mechanisms of action and beneficial effects of senotherapy.

105. Li S, Yuan S, Zhao Q, Wang B, Wang X, Li K. Quercetin enhances chemotherapeutic effect of doxorubicin against human breast cancer cells while reducing toxic side effects of it. Biomedicine \& pharmacotherapy $=$ Biomedecine \& pharmacotherapie. 2018;100:441-7. https://doi.org/10.1016/j. biopha.2018.02.055.

106. Li SZ, Li K, Zhang JH, Dong Z. The effect of quercetin on doxorubicin cytotoxicity in human breast cancer cells. Anti-cancer agents in medicinal chemistry. 2013;13(2):352-5. https://doi.org/ 10.2174/1871520611313020020.

107. Zhu Y, Tchkonia T, Pirtskhalava T, Gower AC, Ding H, Giorgadze N, et al. The Achilles' heel of senescent cells: from transcriptome to senolytic drugs. Aging cell. 2015;14(4):64458. https://doi.org/10.1111/acel.12344.

108.• Ellison-Hughes GM. First evidence that senolytics are effective at decreasing senescent cells in humans. EBioMedicine. 2020;56: 102473. https://doi.org/10.1016/j.ebiom.2019.09.053. First 
clinical evidence of senolytic efficacy in depletic senescent cells in humans.

109. Guerrero A, Herranz N, Sun B, Wagner V, Gallage S, Guiho R, et al. Cardiac glycosides are broad-spectrum senolytics. Nature metabolism. 2019;1(11):1074-88. https://doi.org/10.1038/ s42255-019-0122-z.

110. Liu Y, Shoji-Kawata S, Sumpter RM Jr, Wei Y, Ginet V, Zhang L, et al. Autosis is a Na+,K+-ATPase-regulated form of cell death triggered by autophagy-inducing peptides, starvation, and hypoxia-ischemia. Proceedings of the National Academy of Sciences of the United States of America. 2013;110(51):20364-71. https:// doi.org/10.1073/pnas.1319661110.

111. Liu Y, Levine B. Autosis and autophagic cell death: the dark side of autophagy. Cell death and differentiation. 2015;22(3):367-76. https://doi.org/10.1038/cdd.2014.143.

112. Nah J, Zhai P, Huang CY, Fernandez AF, Mareedu S, Levine B, et al. Upregulation of Rubicon promotes autosis during myocardial ischemia/reperfusion injury. The Journal of clinical investigation. 2020;130(6):2978-91. https://doi.org/10.1172/ JCI132366.

113. Jiang K, Xu Y, Wang D, Chen F, Tu Z, Qian J, et al. Cardioprotective mechanism of SGLT2 inhibitor against myocardial infarction is through reduction of autosis. Protein \& cell. 2021. https://doi.org/10.1007/s13238-020-00809-4.

114. Sciarretta S, Maejima Y, Zablocki D, Sadoshima J. The role of autophagy in the heart. Annual review of physiology. 2018;80:126. https://doi.org/10.1146/annurev-physiol-021317-121427.

115. Rajendran P, Alzahrani AM, Hanieh HN, Kumar SA, Ben Ammar $\mathrm{R}$, Rengarajan T, et al. Autophagy and senescence: a new insight in selected human diseases. Journal of cellular physiology. 2019;234(12):21485-92. https://doi.org/10.1002/jcp.28895.

Publisher's Note Springer Nature remains neutral with regard to jurisdictional claims in published maps and institutional affiliations. 